\title{
In reply: Postoperative cognitive dysfunction after noncardiac surgery: effects of metabolic syndrome
}

\author{
Judith A. Hudetz $\cdot$ Paul S. Pagel
}

Received: 28 July 2011/Accepted: 10 August 2011/Published online: 1 September 2011

(C) Japanese Society of Anesthesiologists 2011

We thank Dr. Sessler for his interest in our recent work and appreciate his astute statistical observation [1]. We used our pilot data to determine sample size [2]. In our pilot study, with a sample size of 28 patients per group, we successfully demonstrated that patients with metabolic syndrome exhibited more profound short-term cognitive deficits after cardiac surgery than did their healthier counterparts. Therefore, we included 30 subjects per group in the current study. The primary outcome for the present investigation was overall cognitive impairment after noncardiac surgery in patients with versus without metabolic syndrome. The incidence of postoperative cognitive dysfunction in patients with metabolic syndrome was $17 / 30$ (and not 13/30; this is an error, and the chi square $P$ value would indeed be equal to 0.176 as Dr. Sessler suggests, if this were the case); therefore, the last sentence of the
Results section (in abstract and main body of manuscript) should read "The prevalence rate of POCD was different in the studied groups (17/30 and 8/30 in patients with versus without metabolic syndrome; $P<0.02)$."

\section{References}

1. Hudetz JA, Patterson KM, Amole O, Riley AV, Pagel PS. Postoperative cognitive dysfunction after noncardiac surgery: effects of metabolic syndrome. J Anesth. 2011;25:337-44.

2. Hudetz JA, Patterson KM, Iqbal Z, Gandhi SD, Pagel PS. Metabolic syndrome exacerbates short-term postoperative cognitive dysfunction in patients undergoing cardiac surgery: results of a pilot study. J Cardiothorac Vasc Anesth. 2011;25:282-7.

This author's reply refers to the letter to the editor at doi:10.1007/s00540-011-1213-5.

J. A. Hudetz $(\square) \cdot$ P. S. Pagel
Department of Anesthesiology,
Clement J. Zablocki Veterans
Administration Medical Center,
5000 W. National Avenue,
Milwaukee, WI 53295, USA
e-mail: judith.hudetz@va.gov

J. A. Hudetz · P. S. Pagel

Medical College of Wisconsin,

8701 Watertown Plank Road,

Milwaukee, WI 53226, USA 